
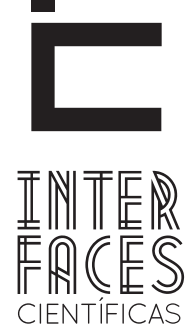

DIREITO

\title{
RESTABELECIMENTO DO PODER FAMLLIAR: REINTEGRAÇÃO À FAMÍLIA NATURAL
}

\section{RESUMO}

Ante a possibilidade dos pais perderem o poder familiar de seus filhos, necessária se faz a análise acerca de restabelecimento de tal vínculo. Assim, o presente artigo tem por objetivo analisar a possibilidade do restabelecimento do poder familiar nos casos cujos pais consigam comprovar a superação da situação que ensejou o processo judicial de destituição. A ação de destituição do poder familiar somente é aplicada em situações excepcionais, contudo, em alguns casos, a família consegue adquirir condições para recuperar a prole e pretende a revisão do julgado. Apesar da falta de previsão legal e dos posicionamentos doutrinários e jurisprudenciais divergentes sobre o assunto, do estudo realizado, conclui-se pela possibilidade do restabelecimento do poder familiar, desde que os pais demonstrem que foram cessadas as causas que levaram à destituição, que a criança ou adolescente não tenha sido adotada e que a medida atenda o melhor interesse dos filhos, de modo a garantir-lhes o direito de serem criados e educados na sua família biológica.

\section{PALAVRAS-CHAVE}

Poder Familiar. Destituição. Restabelecimento. 


\section{ABSTRACT}

Against the possibility of parents lose the family power of his sons, is necessary if the analysis about restoring such a bond. Thus, this article aims to analyze the possible re-establishment of family power in cases whose parents are able to prove the overcoming of the situation giving rise to the judicial process of dismissal. The familiar power of impeachment action is applied only in exceptional situations, however, in some cases, the family can acquire conditions to recover the offspring and intends to review the trial. Despite the lack of legal provisions and differing doctrinal and jurisprudential positions on the subject, the study concludes the possible re-establishment of family power, since the fathers were stopped demonstrating that the causes that led to the dismissal, the child or teen has not been adopted and that the measure meets the best interests of children, in order to guarantee them the right to be raised and educated in their biological family.

\section{KEYWORDS}

Family Power. Dismissal. Restoration.

\section{RESUMEN}

En contra de la posibilidad de que los padres pierdan el poder de la familia de sus hijos, se hace necesario el análisis sobre la restauración de dicha unión. Por lo tanto, este artículo tiene como objetivo analizar la posibilidad del restablecimiento del poder de la familia en los casos cuyos padres son capaces de demostrar la superación de la situación que dio lugar al proceso judicial de destitución. La acción de destitución del poder familiar solamente se aplica en situaciones excepcionales, sin embargo, en algunos casos, la familia puede adquirir condiciones para recuperar la prole y tiene la intención de revisar el juicio. A pesar de la falta de previsión legal y de los posicionamien- tos doctrinales y jurisprudenciales divergentes sobre el tema, del estudio realizado llegamos a la conclusión de la posible restauración del poder de la familia, desde que los padres demuestren que fueron cesadas las causas que llevaron a la destitución, que el niño o adolescente no haya sido adoptado y que la medida cumpla con los mejores intereses de los hijos, a fin de garantizarles el derecho de ser criados y educados en su familia biológica.

\section{PALABRAS CLAVE}

Poder familiar. Destitución. Restauración. 


\section{INTRODUÇ̄̃̃O}

Frente às inúmeras possibilidades dos pais, pela razão que for, de perderem o poder familiar em relação aos filhos, é que se buscou analisar a eventual possibilidade de se restabelecer este vínculo, desde que solucionados os motivos que ensejaram a medida judicial em questão.

Os relacionamentos familiares são permeados de inúmeros direitos e deveres que constantemente sofrem abusos ou omissões, mais comumente nas relações entre pais e filhos quando do exercício do poder familiar.

Em algumas situações, principalmente quando ocorre o descumprimento dos deveres parentais, o Estado necessita intervir nas relações familiares, podendo suspender e até destituir o poder familiar dos pais faltosos.

Ocorre que, em alguns casos, os pais conseguem superar os motivos que ensejaram a destituição do poder familiar e pretendem recuperar a prole.

Para atender ao objetivo do presente artigo, serão abordadas questões atinentes ao exercício, conceito e características do poder familiar, seguindo com o estudo da intervenção estatal, mais precisamente os casos de suspensão e perda judicial do poder familiar.

Na sequência, o enfoque será dado para alguns posicionamentos doutrinários e jurisprudenciais acerca da possibilidade do restabelecimento do poder familiar, bem como, a previsão legal estrangeira sobre o assunto para posterior conclusão, com a realização de análise da aplicação dos princípios do melhor interesse da criança e do adolescente e do direito à convivência familiar aos casos de restabelecimento do poder familiar.

\section{PODER FAMILIAR}

No início da vida, principalmente nos períodos da infância e da adolescência, todo ser humano necessita de alguém responsável por sua criação, educação e proteção, cabendo, por natureza, aos pais realizar esta incumbência e na sua falta, algum adulto responsável.
A esse conjunto de direitos e deveres dos pais na criação dos filhos, enquanto menores, encontra-se no ordenamento jurídico a figura do poder familiar.

A palavra poder familiar corresponde ao que era anteriormente denominado pátrio poder, termo que remonta ao direito romano: pater potestas e significava o direito absoluto e ilimitado conferido ao chefe da organização familiar, que era o pai, sobre a pessoa dos filhos (DIAS, 2005).

Com a igualdade de direitos e obrigações entre homens e mulheres, prevista no artigo $5^{\circ}$, inciso I, da Constituição Federal, a expressão pátrio poder tornou-se inapropriada, ocasionando a alteração da denominação pelo Código Civil de 2002 para poder familiar, muito mais adequada ao texto constitucional e à realidade social. A esse respeito, Elias (2004, p. 22), afirma que “a troca de 'pátrio' por 'familiar' quer, sem dúvida, enfatizar que referido poder deve ser exercido tanto pelo pai como pela mãe".

Trilhando a mesma senda, o Estatuto da Criança e do Adolescente, prevê em seu artigo 21, que o poder familiar será exercido em igualdade de condições entre pai e mãe, assegurando-lhes o direito de buscarem na autoridade judiciária a solução da divergência.

Desenvolveu-se, de acordo com Gomes (2009), uma tendência pela consagração do princípio da paridade conjugal, de forma que ambos os pais devem ter o mesmo grau de autoridade em relação ao filho.

Definido a quem cabe o exercício do poder familiar, cumpre citar alguns conceitos, visto que coube à doutrina conceituar o instituto, porquanto o ordenamento positivo ateve-se mais à sua regulamentação do que à sua definição.

Entre os inúmeros conceitos existentes, Maciel (2007) define o poder familiar como sendo um complexo de direitos e deveres pessoais e patrimoniais em relação ao filho menor, não podendo os genitores renunciar, tampouco transferi-lo gratuita ou onerosamente a terceiros.

Corroborando, Dias (2005, p. 381) dispõe que:

Tentar definir poder familiar nada mais é do que tentar enfeixar o que compreende o conjunto de faculdades 
encomendadas aos pais, como instituição protetora da menoridade, com o fim de lograr o pleno desenvolvimento e a formação integral dos filhos, seja físico, mental, moral, espiritual ou socialmente. A autoridade parental está impregnada de deveres não apenas no campo material, mas, principalmente, no campo existencial, devendo os pais satisfazer outras necessidades dos filhos, notadamente de índole afetiva.

Como visto, aos pais incumbe a importante tarefa de preparar seus filhos para vida e em razão disto, preocupou-se o legislador em traçar normas e meios para auxiliá-los nesta missão.

As funções do poder familiar estão regulamentadas basicamente em três dispositivos legais, que são o artigo 229 da Constituição Federal, o artigo 1.634 do Código Civil e o artigo 22 do Estatuto da Criança e do Adolescente.

0 caráter de dever do poder familiar está expresso no artigo 229 da Constituição Federal, cujo texto dispõe que "os pais têm o dever de assistir, criar e educar os filhos menores".

o Código Civil tratou de elencar os direitos e deveres incumbidos aos pais durante o exercício do poder familiar, estabelecendo no artigo 1.634 as funções de direção da criação e educação, companhia, guarda, representação, exigência de obediência, entre outros.

Por sua vez, o artigo 22 do Estatuto da Criança e do Adolescente prevê:

Art. 22. Aos pais incumbe o dever de sustento, guarda e educação dos filhos menores, cabendo-lhes ainda, no interesse destes, a obrigação de cumprir e fazer cumprir as determinações.

Por fim, ainda cabe mencionar que o poder familiar apresenta algumas características próprias, que segundo Comel (2003) são: a irrenunciabilidade, porque os pais não podem abrir mão do seu exercício, segundo conveniências ou em proveito próprio; a intransmissibilidade, porque é inerente aos que ostentam a condição de pai ou mãe e a imprescritibilidade, porque não se extingue pelo desuso.

De todo o exposto, verifica-se que o poder familiar compreende a função irrenunciável, inalienável e in- delegável dos pais de criar e educar os filhos durante a menoridade, visando seu pleno desenvolvimento físico, mental, moral, social e espiritual.

\section{DESTITUIÇÃO DO PODER FAMILIAR}

Considerando que a família constitui o alicerce da sociedade e que o poder familiar deve ser exercido no interesse dos filhos menores, compete ao Estado auxiliar e fiscalizar o cumprimento de tais deveres, a teor do que prevê o artigo 227, caput, da Constituição Federal:

Art. 227. É dever da família, da sociedade e do Estado assegurar à criança, ao adolescente e ao jovem, com absoluta prioridade, o direito à vida, à saúde, à alimentação, à educação, ao lazer, à profissionalização, à cultura, à dignidade, ao respeito, à liberdade e à convivência familiar e comunitária, além de colocá-los a salvo de toda forma de negligência, discriminação, exploração, violência, crueldade e opressão.

Tais deveres, também, são reafirmados no artigo $4^{\circ}$ do Estatuto da Criança e do Adolescente.

Assim, sempre que se constatar a existência de algum fato incompatível com o exercício do poder familiar, poderá o Estado intervir, a fim de preservar o desenvolvimento saudável dos infantes. A esse respeito, Akel (2009) afirma que a ingerência do Estado tem por objetivo salvaguardar os interesses pessoais e patrimoniais dos menores, de modo a coibir arbitrariedades por parte dos pais.

Para tanto, o Estatuto da Criança e do Adolescente prevê em seus artigos 129 e 249 algumas medidas de auxílio, obrigacionais e sancionatórias. Entre elas estão os casos em que o titular do poder familiar pode ser privado do seu exercício, temporária ou definitivamente, que são a suspensão e a perda ou destituição do poder familiar.

A suspensão está prevista no artigo 1.637 do Código Civil e está relacionada ao abuso de autoridade, à falta aos deveres inerentes ao poder familiar, à ruína dos bens dos filhos e ainda, à condenação por sentença irrecorrível em virtude de crime cuja pena exceda a dois anos de prisão. 
Sobre a suspensão do poder familiar, Comel (2003, p. 264) afirma:

Consiste numa restrição imposta judicialmente àquele que exerce o poder familiar e que vier ou a abusar de sua função em prejuízo do filho, ou a estar impedido temporariamente de exercê-la, pela qual se retira parcela de sua autoridade. E disso, também, conclui-se que a suspensão não tem o caráter de definitividade, pois consiste em medida provisória, com duração determinada, destinada a ter vigência enquanto perdurar a situação que ensejou, ou seja, enquanto necessária e útil aos interesses do filho.

Venosa (2001, p. 298) afirma que “a suspensão é medida menos grave do que a destituição ou perda porque, cessados os motivos, extinta a causa que a gerou, pode ser restabelecido o poder paternal".

Corroborando, Maciel (2008, p. 113) sustenta:

A distinção entre os dois institutos estabelece-se pela graduação da gravidade das causas que as motivam e pela duração de seus efeitos. Se, por um lado, a suspensão é provisória e fixada ao criterioso arbítrio do juiz, dependendo do caso concreto e no interesse dos menores, a perda do poder familiar pode revestir-se de caráter irrevogável, como na situação de transferência do poder familiar pela adoção.

Não obstante, para o nosso estudo, importa discorrer com mais profundidade sobre a situação da perda ou destituição do poder familiar, em razão de ser considerada a medida mais grave e uma vez destituídos do encargo, não há previsão legal para os pais promoverem o seu restabelecimento.

A perda ou destituição do poder familiar está prevista no artigo 1.638 do Código Civil, que estabelece os casos em que caberá:

Art. 1.638. Perderá por ato judicial o poder familiar o pai ou a mãe que:

I - castigar imoderadamente o filho;

II - deixar o filho em abandono;

III - praticar atos contrários à moral e aos bons costumes;

IV - incidir, reiteradamente, nas faltas previstas no artigo antecedente.
Sobre as causas previstas no dispositivo legal, Akel (2009, p. 51) comenta;

[...] que a perda do poder familiar está estribada em motivos mais gravosos do que aqueles que ensejam sua suspensão. As causas elencadas no texto da lei são exaustivas, não permitindo interpretação extensiva, uma vez que a sanção da destituição é medida excepcional, devendo sempre visar aos interesses do menor e ao bem-estar incondicional da prole.

A decisão judicial que decreta a destituição do poder familiar, também, está colocada como uma das formas de extinção do poder familiar, pelo artigo 1.635 do Código Civil:

Art. 1.635. Extingue-se pode familiar;

I - pela morte dos pais ou do filho;

II - pela emancipação, nos termos do art. $5^{\circ}$, parágrafo único;

III - pela maioridade;

IV - pela adoção;

V - por decisão judicial, na forma do art. 1.638.

Comel (2003, p. 296) comenta que a colocação deste último inciso como causa de extinção do poder familiar "acabou por não permitir, de regra, que o pai afastado fosse reconduzido à função", ensejando assim, posicionamentos diversos sobre a possibilidade do restabelecimento do poder familiar.

Ressalte-se ainda que a falta de recursos materiais na família não enseja a suspensão ou a perda do poder familiar, consoante artigo 23 do Estatuto da Criança e do Adolescente, competindo ao Estado incluir a família carente em programas de auxílio.

Verificadas as situações que ensejam a perda do poder familiar, cabe discorrer sobre o rito processual a ser observado, uma vez que, tanto a suspensão como a destituição do poder familiar só podem ser decretadas judicialmente, em procedimento que assegure a ampla defesa dos interessados, a teor do contido no artigo 24 do Estatuto da Criança e do Adolescente.

Para tratar sobre o rito processual, o Estatuto da Criança e do Adolescente reservou no capítulo que versa sobre os procedimentos, os artigos 155 a 163, que tratam da perda e da suspensão do poder familiar. 
A autoridade competente será o Juiz da Infância e Juventude ou o Juiz de Família, conforme o menor esteja ou não em situação de risco, a teor do contido no artigo 148 do Estatuto da Criança e do Adolescente.

A legitimidade ativa é do Ministério Público ou de quem tenha legítimo interesse, nos termos do artigo 155 do Estatuto da Criança e do Adolescente. A esse respeito, Azevedo (APUD COMEL, 2003, p. 279) dispõe:

É o ECA, no art. 155, que estende a legitimidade ativa a quem tenha lídimo interesse, restrita que está no Código Civil a qualquer parente. Com isso, não apenas os parentes do menor podem propor a suspensão ou modificação, mas, também, qualquer terceiro que se ache investido de legitimidade e interesse para agir, assim se qualificando qualquer pessoa que reúna condições para o exercício da ação, como por exemplo, pretendentes à tutela ou adoção.

Por fim, o prazo máximo previsto para a conclusão do procedimento será de 120 dias e a sentença que decretar a perda ou a suspensão do poder familiar será averbada à margem do registro de nascimento da criança ou adolescente, a teor do contido no artigo 163 e parágrafo único do Estatuto da Criança e do Adolescente.

Uma vez decretada a destituição do poder familiar, a relação jurídica existente entre pai e filho é extinta e consequentemente, as crianças permanecerão em abrigos até atingirem a maioridade, salvo se forem colocadas em família substituta, nas formas de guarda ou adoção.

Desse modo, observa-se que a legislação brasileira é repleta de dispositivos que visam a observância dos deveres parentais, que vão desde medidas de auxílio até sancionatórias, a exemplo da destituição do poder familiar, sem, contudo, prever a possibilidade da sua restauração, nos casos cujas circunstâncias da perda foram superadas pelos pais.

\section{RESTABELECIMENTO DO PODER FAMILIAR}

Tanto o Código Civil de 1916 como o Código Civil de 2002 silenciaram a respeito da possibilidade do restabelecimento do poder familiar. Da mesma forma, o Estatuto da Criança e do Adolescente não prevê for- mas de recuperação do poder familiar pelos pais que foram destituídos em processo judicial.

Não havendo previsão legal sobre o assunto, uma pesquisa doutrinária e jurisprudencial se torna necessária para melhor discorrer sobre a possibilidade da recuperação do poder familiar, visto que os posicionamentos doutrinários e jurisprudenciais existentes sobre o tema não são uníssonos.

Entre os doutrinadores que entendem ser a medida definitiva, Comel (2003) cita o posicionamento de Antonio Cezar Lima da Fonseca, que na defesa da sua tese na obra A ação de destituição do pátrio poder, sustentou que a destituição era definitiva, porque se tratava da mais grave sanção prevista em lei e o juiz vendo que o pai podia emendar-se, não devia decretá-la, mas sim, suspender ou adotar outra medida. Também acrescentou que na sua vida funcional nunca viu pais destituídos se emendarem ou buscarem reintegração da potestade perdida.

Nesse sentido, a jurisprudência catarinense já proferiu julgamento:

APELAÇÃO CÍVEL. AÇÃO DE RESTITUIÇÃO DE PODER FAMILIAR. APELANTES QUE ALEGAM NÃO MAIS PERSISTIREM OS FATOS QUE GERARAM A DESTITUIÇÃO DO PODER FAMILIAR, REQUERENDO A RETIRADA DAS MENORES DO ABRIGO ONDE SE ENCONTRAM. AMPLA ANÁLISE DE PROVAS NA AÇÃO DE DESTITUIÇÃO DO PODER FAMILIAR TRANSITADA EM JULGADO. SENTENÇA EXTINGUINDO A AÇÃO PELA OCORRÊNCIA DA COISA JULGADA. ART. 267, V, DO CÓDIGO DE PROCESSO CIVIL. MANUTENÇÃO. PRECEDENTES DESTA CORTE. DEMAIS PEDIDOS PREJUDICADOS. “1. Não se cogita de retorno da guarda aos pais biológicos ou de estabelecer direito de visitas, quando estes já foram destituídos do poder familiar em relação à filha, já tendo a ação transitado em julgado. 2. É consabido que a destituição do poder familiar rompe os liames jurídicos entre pais e filhos. 3. Descabe à parte postular o restabelecimento da guarda da filha pois essa questão está implícita com a destituição do poder familiar e que já foi alvo de decisão judicial, sendo atacada pelo recurso próprio e no momento oportuno, mas que restou desprovido. Recurso desprovido." (TJRS, Apelação Cível n. 70041024233, Relator: Des. Sérgio Fernando de Vasconcellos Chaves, j. em 27.04.2011) 
RECURSO CONHECIDO E DESPROVIDO. (TJSC, Apelação Cível no 2013.039744-6, em 10-9-2013, Câmara Especial Regional de Chapecó, Juiz rel. Artur Jenichen Filho, Concórdia).

Da análise de tais posicionamentos depreende-se que a medida de destituição do poder familiar, ainda, é tida por muitos como irrevogável, definitiva e de efeitos permanentes, o que afasta por completo a possibilidade dos pais recuperarem a prole.

De outro norte, existem aqueles que defendem a revogação da medida, desde que cessadas as causas que ensejaram a destituição do poder familiar e seja a medida benéfica ao menor. Entre os quais, citam-se Viana, Gomes e Santos Neto.

Viana (APUD VENOSA, 2001, p. 299) afirma "que o que foi destituído do pátrio poder pode ser nele reinvestido, provando judicialmente que as razões que determinaram a medida cessaram".

Para Gomes (2000, p. 399): "o pátrio poder perdido pode ser restabelecido, provada a regeneração do pai ou desaparecida a causa que determinou. A reintegração no exercício do múnus, de que o pai foi privado, deve ser pleiteada judicialmente pelo interessado".

Contribuindo com o entendimento, Santos Neto (APUD COMEL, 2003, p. 296):

[...] ao argumento de que, se o Estado podia investir terceiros idôneos na função paterna, por que não poderia restituir o filho ao próprio pai, desde que recuperada a idoneidade? Não como direito dos pais à recuperação, mas tão-somente como direito do menor.

Comel (2003) ainda esclarece que alguns doutrinadores que defendem o caráter revogável da medida fundamentam o entendimento no antigo Código de Menores de 1927, que admitia a reintegração mediante o preenchimento de requisitos, entre os quais a prova da regeneração ou o desaparecimento da causa de inibição e não haver inconveniência na volta do menor ao poder familiar.

No direito comparado, a maioria das legislações admite o restabelecimento do poder familiar, desde que cessadas as causas que ensejaram a destituição e a recondução seja favorável ao menor. Entre os quais, cita-se o Código Civil espanhol (art. 170-1, CCE), a legislação civil de Portugal (art. 1.916, CC) e o direito civil argentino (art. 308, CC) (AKEL, 2009).

Nesse sentido, a jurisprudência paulista proferiu o seguinte acórdão:

\begin{abstract}
Código Civil e Estatuto da Criança e do Adolescente. Ação de restituição do poder familiar exercido por pai sobre quatro filhos menores - Genitora que se encontra em local incerto e não sabido - Sentença que julgou extinto o processo em relação a três crianças, tendo em vista a falta de interesse de agir do requerente e a impossibilidade jurídica do pedido, vez que elas se encontram em estágio de convivência com família substituta, determinando ainda o MM. Juiz, excepcionalmente, no que diz respeito a um dos menores, informações sobre eventual existência de casais interessados em sua adoção - Ausência de dispositivo legal que vete o requerimento de restituição do poder familiar por genitores destituídos do poder familiar através de sentença definitiva - Possibilidade de o pai biológico reaver seus filhos, desde que comprovada a alteração na situação fática que autorizou a destituição de tal poder - E não há nos autos informação acerca de sentença judicial que concedeu a adoção dos petizes - Apelação provida a fim de determinar a remessa dos autos ao juízo de origem para a prossecução do feito até a prolação da sentença de mérito. (TJSP, Apelação Cível nº 0533009-47.2010, em 28-3-2011, Câmara Especial do TJSP, rel. Des. Reis Kuntz, Capão Bonito).
\end{abstract}

Por fim, além dos posicionamentos doutrinários e jurisprudenciais é oportuno consignar que, atualmente, tramita no Congresso Nacional o Projeto de Lei ${ }^{\circ}$ 2.285/2007, da autoria do Deputado Federal Sérgio Barradas Carneiro (PT-BA), que dispõe sobre o Estatuto das Famílias, cujo artigo 95 dispõe: "É possível, no melhor interesse do filho, o restabelecimento da autoridade parental por meio de decisão judicial".

Ainda, sobre o pedido, Maciel (2008) afirma que o postulante deverá demonstrar os fundamentos fáticos e jurídicos que ensejaram e perda do poder familiar, bem como, os fatos novos que demonstrem a capacidade de voltar a exercer o encargo, na forma do artigo 471, I, do Código de Processo Civil.

Sob esta ótica, o que a lei permite é a possibilidade de ser proferido um novo julgamento sobre fatos 
novos, que constituem uma nova causa de pedir, ensejando uma nova coisa julgada.

Além dos pais comprovarem que foram cessadas as causas que os destituíram do poder familiar, também terão que provar que o restabelecimento atende o interesse do filho menor, visto que o Estatuto da Criança e do Adolescente ao adotar a doutrina da proteção integral (art. $1^{\circ}$ ), reconhece a criança e o adolescente como sujeitos de direitos, direcionando todas as medidas ao seu melhor interesse.

Além da proteção integral, o Estatuto da Criança e do Adolescente assegura à criança e ao adolescente, o direito à convivência familiar, cujo artigo 19, caput e $\S 3^{\circ}$ dispõe:

Art. 19. Toda criança ou adolescente tem direito a ser criado e educado no seio da sua família e, excepcionalmente, em família substituta, assegurada a convivência familiar e comunitária, em ambiente livre da presença de pessoas dependentes de substâncias entorpecentes. [...]

$\S 3^{\circ}$ A manutenção ou reintegração de criança ou adolescente à sua família terá preferência em relação a qualquer outra providência, caso em que será esta incluída em programas de orientação e auxílio, nos termos do parágrafo único do art. 23, dos incisos I e IV do caput do art. 101 e dos incisos I a IV do caput do art. 129 desta Lei.

Entre as medidas de proteção previstas no estatuto está no artigo 100, inciso X a de prevalência da família natural:

Art. 100. Na aplicação das medidas levar-se-ão em conta as necessidades pedagógicas, preferindo-se aqueles que visem ao fortalecimento dos vínculos familiares e comunitários.

[...]

X - prevalência da família: na promoção de direitos e na proteção da criança e do adolescente deve ser dada prevalência às medidas que os mantenham ou reintegrem na sua família natural ou extensa ou, se isto não for possível, que promovam a sua integração em família substituta; [...]

Oportuno, também, mencionar, que cabe no pedido de restabelecimento do poder familiar, a oitiva da parte mais interessada, que são os filhos, pois se na colocação em família substituta o Estatuto da Criança e do Adolescente, em seu artigo 28 , $\S 1^{\circ}$ permite tal possibilidade porque não nos pedidos de reintegração à família natural.

Por fim, sobre a forma procedimental para confecção do pedido de restabelecimento do poder familiar, parece mais acertada a disposta na tese apresentada pelo promotor de justiça Epaminondas da Costa, no XXIV Congresso da Associação Brasileira de Magistrados e Promotores de Justiça e Defensores Públicos da Infância e Juventude, realizado em Natal - RN, que orienta para formulação de um requerimento de "restauração" do registro (art. 109 da LRP) a ser feito por curador especial nomeado pelo juiz, nos termos do art. 141, $\S 1^{\circ}$ do ECA, atuando o Ministério Público no processo como fiscal da lei, não sendo necessária a propositura de nova ação por inexistir pretensão resistida entre pais e filhos que almejam a manutenção do vínculo biológico. Acrescenta:

\begin{abstract}
Afora isto, averba-se no registro público apenas a destituição ou a suspensão do poder familiar, sem o cancelamento do registro. Noutros termos, cuida-se de uma simples anotação (averbação), podendo ser cancelada posteriormente, contanto que sejam cumpridas as formalidades legais próprias, assim como ocorre com as anotações no registro imobiliário, passíveis expressamente de cancelamento (cf. art. 250 da Lei n. 6.015 de 1973). Outrossim, é inconcebível que a presente situação seja resolvida por meio do instituto da adoção, o qual ser destina a estabelecer a relação de parentesco entre pessoas desvinculadas biologicamente.
\end{abstract}

Por todo o exposto, não havendo adoção do infante após a destituição do poder familiar e verificado que a família biológica superou as causas que ensejaram a perda da prole e a medida atende os interesses do menor, nada mais justo do que reconduzir o filho aos pais, promovendo o restabelecimento do poder familiar.

\section{CONSIDERAÇÕES DERRADEIRAS}

Existem vários posicionamentos doutrinários sobre a revogabilidade da medida de destituição do poder familiar. Alguns juristas entendem que uma vez decido 
pela destituição, opera-se a coisa julgada material e não mais se discute a possibilidade do restabelecimento, dando à medida o caráter definitivo e irrevogável.

Embora a legislação seja enfática ao afirmar a importância da função dos pais na criação dos filhos, poucas são as medidas efetivas no sentido de restabelecer o poder familiar perdido.

Para os casos de violações e/ou omissões dos deveres dos pais em relação à prole existem, também, inúmeras medidas e penalidades aplicáveis, que vão desde a aplicação de medidas de auxílio até a suspensão ou perda do poder familiar.

A partir disso, observa-se que o pedido de restabelecimento do poder familiar formulado pelos pais destituídos deve ser recebido pelo judiciário com a atenção que o caso merece, não podendo ser simplesmente rejeitado com base nas normas do processo civil ou na ausência de previsão legal sobre o assunto, o que poderia tirar dos filhos a oportunidade de crescer num ambiente familiar, garantido constitucionalmente.

Além do mais, o Estatuto da Criança e do Adolescente destaca como medidas de proteção o fortalecimento dos vínculos familiares e a reintegração à família natural, sendo a colocação em família substituta uma exceção à regra estatutária.

Por fim, havendo qualquer possibilidade de uma criança ou adolescente ficar na sua família natural, todos os esforços devem ser empreendidos, uma vez que a família é considerada o lugar ideal e necessário para o pleno desenvolvimento de seus integrantes.

\section{REFERÊNCIAS}

AKEL, Ana Carolina Silveira. Guarda Compartilhada: um avanço para a família. 2.ed. São Paulo: Atlas, 2009

BRASIL. Código de Processo Civil. Vade Mecum/ obra coletiva de autoria da Editora Saraiva com a colaboração de Luiz Roberto Curia, Lívia Céspedes e Juliana Nicoletti. 14.ed. Atual. e ampl. São Paulo: Saraiva, 2012.
BRASIL. Código Civil. Vade Mecum/obra coletiva de autoria da Editora Saraiva com a colaboração de Luiz Roberto Curia, Lívia Céspedes e Juliana Nicoletti. 14.ed. Atual. e ampl. São Paulo: Saraiva, 2012.

BRASIL. Código Penal. Vade Mecum/obra coletiva de autoria da Editora Saraiva com a colaboração de Luiz Roberto Curia, Lívia Céspedes e Juliana Nicoletti. 14.ed. Atual. e ampl. São Paulo: Saraiva, 2012.

\section{BRASIL. Constituição (1988). Constituição da} República Federativa do Brasil. Vade Mecum/ obra coletiva de autoria da Editora Saraiva com a colaboração de Luiz Roberto Curia, Lívia Céspedes e Juliana Nicoletti. 14.ed. Atual. e ampl. São Paulo: Saraiva, 2012.

BRASIL. Estatuto da Criança e do Adolescente. Vade Mecum/obra coletiva de autoria da Editora Saraiva com a colaboração de Luiz Roberto Curia, Lívia Céspedes e Juliana Nicoletti. 14.ed. Atual. e ampl. São Paulo: Saraiva, 2012.

\section{BRASIL. Projeto de Lei nº 2.285/2007,} que dispõe sobre o Estatuto das Famílias. Disponível em: <http://www.camara.gov.br/ proposicoesWeb/fichadetramitacao?idProposic ao=373935>. Acesso em: 30 mar. 2014.

\section{BRASIL. Tribunal de Justiça do Estado de Santa}

Catarina. Apelação Cível nº 2013.039744-6, da Câmara Especial Regional de Chapecó, 10 de setembro de 2013. Disponível em: <http://www.tjsc. jus.br>. Acesso em: 28 mar. 2014.

BRASIL. Tribunal de Justiça do Estado de São Paulo. Apelação Cível nº 0533009-47.2010, da Câmara Especial do Tribunal de Justiça do Estado de São Paulo, 28 de março de 2011. Disponível em: <http:// www.tjsp.jus.br>. Acesso em: 28 mar. 2014.

CASTRO, Lúcia Maria Xavier. In: CURY, Munir; AMARAL E SILVA, Antônio Fernando da; MENDEZ, 
Emílio Garcia. Estatuto da Criança e do Adolescente

Comentado. 2.ed. São Paulo: Malheiros Editores Ltda, 2000.

COMEL, Denise Damo. Do poder familiar. São Paulo: Revista dos Tribunais, 2003.

COSTA, Epaminondas da. Destituição do poder familiar frustrada: restabelecimento jurídico do vínculo deôntico da filiação biológica.

\section{Congresso da Associação Brasileira de} Magistrados, Promotores de Justiça e Defensores Públicos da Infância em Juventude. Natal, 2012, Trabalhos apresentados no evento. Disponível em: <http://www.ammp.org.br/inst/artigo/Artigo-61. pdf>. Acesso em: 30 mar. 2014.

DIAS, Maria Berenice. Manual de direito das

famílias. Porto Alegre: Livraria do Advogado, 2005.

ELIAS, Roberto João. Comentários ao Estatuto da

Criança e do Adolescente. 2.ed. São Paulo: Saraiva, 2004.
ELIAS, Roberto João. Direitos fundamentais da criança e do adolescente. São Paulo: Saraiva, 2005.

FONSECA, Antonio Cezar de Lima da. O poder familiar e o novo código civil. In: AZAMBUJA, Maria Regina Fay de; SILVEIRA, Maritana Viana; BRUNO, Denise Duarte. Infância em família: um compromisso de todos. Porto Alegre, 2004.

GOMES, Orlando. Direito de família. 12.ed. Rio de Janeiro: Forense, 2000.

MACIEL, Kátia Regina Lobo Andrade. Curso de direito da criança e do adolescente: aspectos teóricos e práticos. Rio de Janeiro: Lumen Juris , 2007.

VENOSA, Sílvio de Salvo. Direito Civil: direito de família. São Paulo: Atlas, 2001. 